\title{
Role of levonorgestrel releasing intrauterine device in management of heavy menstrual bleeding: a conservative approach
}

\author{
Kalpana Singh*, Geetam Bharati, Dipali Prasad, Smita Kumari
}

Department of Reproductive Biology, Indira Gandhi Institute of Medical Sciences, Patna, Bihar, India

Received: 05 December 2016

Accepted: 31 December 2016

\author{
*Correspondence: \\ Dr. Kalpana Singh, \\ E-mail: drkalpana1@yahoo.com
}

Copyright: (c) the author(s), publisher and licensee Medip Academy. This is an open-access article distributed under the terms of the Creative Commons Attribution Non-Commercial License, which permits unrestricted non-commercial use, distribution, and reproduction in any medium, provided the original work is properly cited.

\begin{abstract}
Background: Heavy menstrual bleeding (HMB) is defined as prolonged ( $>7$ days) or excessive menstrual blood loss greater than or equal to $80 \mathrm{ml}$ per menstrual cycle. The objective of the study was to assess the efficacy, acceptability and side effects of LUS IUS in women with heavy menstrual bleeding.

Methods: 42 women with heavy menstrual bleeding with or without associated dysmenorrhoea or chronic pelvic pain and had no contraindication to IUS insertion were included in the study. Patients having active genital tract infection, suspicion of pregnancy, uterine fibroids $>2.5 \mathrm{~cm}$ in size or sub mucosal distorting the uterine cavity, uterine size $>12$ weeks, atypical endometrial hyperplasia or malignancy, abnormal cervical cytology, coagulopathy or liver disease were excluded from the study. Preliminary endometrial biopsy was done to rule out malignancy and LNG IUS was inserted under anaesthesia. Women were followed for 3,6,12 and 24 months post insertion.

Results: In first 3 months, 20\% patients achieved normal menstrual cycle, and at 6 months $44.44 \%$ had scanty menstrual flow and after 1 year of use $81.5 \%$ achieved amenorrhoea. In initial 3 months $37.5 \%$ patients had irregular heavy bleeding, which reduced to $13.89 \%$ at 6 months and $0 \%$ at 1 year follow up. Irregular spotting was second most complaint in $32.5 \%$ patients in initial 3 months that persisted in $7.4 \%$ patients at 1year follow up. In $5.0 \%$ patients, there was spontaneous expulsion of the device in first 3 menstrual cycles. After 3 months of use 57.5\% patients were satisfied with the device and at the end of 1 year $92.5 \%$ were satisfied.

Conclusions: LNG IUS is highly effective in controlling blood loss, well tolerated and better alternative for hysterectomy with higher user satisfaction in all age group of women.
\end{abstract}

Keywords: Adenomyosis, Endometrial hyperplasia, Endometriosis, Fibroid, Heavy menstrual bleeding, LNG IUS

\section{INTRODUCTION}

Heavy menstrual bleeding (HMB) is defined as prolonged ( $>7$ days) or excessive menstrual blood loss greater than or equal to $80 \mathrm{ml}$ per menstrual cycle. ${ }^{1} \mathrm{It}$ interferes with a woman's physical, social, emotional and/or material quality of life. Abnormal uterine bleeding is a common reason for consulting a gynecologist and hysterectomy is often used to treat women with menorrhagia but medical therapy may be a successful alternative. ${ }^{2}$ Levonorgestrel-releasing intrauterine device (LNG-IUS) has become one of the most acceptable medical treatments for menorrhagia, reducing referrals to specialists and decreasing the need for operative gynaecological surgery. ${ }^{3}$ Levonorgestrel is released from this system at a rate of $20 \mathrm{mcg} / 24$ hours. It suppresses endometrial growth, the glands of the endometrium become atrophic and the epithelium becomes inactive. Along with the high contraceptive efficacy, LNG-IUS has shown benefits and improvement of symptoms in menorrhagia, adenomyosis and endometriosis. ${ }^{4,5}$ LNGIUS device has also been found to be cost-effective with less side effects and to increase the quality of life (QOL). ${ }^{6}$ The QOL of women treated with the LNG-IUS is markedly improved, causing high levels of patient satisfaction. ${ }^{7}$ Hence, this study was conducted to evaluate 
the efficacy, acceptability and side effects of LNG-IUS in women with heavy menstrual bleeding.

\section{METHODS}

It was a prospective interventional study conducted over a period between september 2013 to august 2015 in Department of reproductive biology, obstetrics \& gynaecology, IGIMS, Patna, Bihar, India. 42 women with heavy menstrual bleeding with or without associated dysmenorrhoea or chronic pelvic pain, fibroid uterus not distorting the endometrium, adenomyosis or endometriosis, having young age or medical or surgical high risk factors making unsuitable for surgery and had no contraindication to IUS insertion were included in the study.

Patients having active genital tract infection, suspicion of pregnancy, uterine fibroids $>2.5 \mathrm{~cm}$ in size or sub mucosal distorting the uterine cavity, uterine size $>12$ weeks, atypical endometrial hyperplasia or malignancy, abnormal cervical cytology, coagulopathy or liver disease were excluded from the study.

All patients underwent a complete general physical, systemic and gynecological examination. CBC, TSH, FBS, LFT, RFT, coagulation profile, ultrasound pelvis, pap smear and endometrial biopsy was done to rule out any malignancy. LNG-IUS was inserted in post menstrual phase under intravenous anesthesia. Follow up was done at 3, 6, 12, 24 months. At each visit menstrual pattern, blood loss and opinion of women for satisfaction was recorded.

\section{RESULTS}

Forty two women with abnormal uterine bleeding were enrolled in the study with mean age of $38.2+6.85$ years. Majority (76.2\%) of the patients belonged to 30-50 years of age. $69 \%$ patients had dysfunctional uterine bleeding, $14.3 \%$ had fibroid uterus, $9.5 \%$ patients had adenomyosis and rest patients had menorrhagia associated with endometriosis and severe dysmenorrohea.

Table 1: Age distribution of the cases.

\begin{tabular}{|l|l|l|}
\hline Age (years) & No of patients & Percentage \\
\hline $21-30$ & 8 & $19.0 \%$ \\
\hline $31-40$ & 17 & $40.5 \%$ \\
\hline $41-50$ & 15 & $35.7 \%$ \\
\hline $51-60$ & 2 & $4.8 \%$ \\
\hline Total & 42 & $100 \%$ \\
\hline
\end{tabular}

In surgical high risk group, we had patients with history of previous 2 LSCS with herniorraphy, previous 4 LSCS, previous 2 LSCS with failed attempt of hysterectomy due to frozen pelvis and morbid obesity. In medical high risk group patients had hypertension, diabetes mellitus, rheumatic heart disease, coronary artery disease, hypothyroidism, bronchial asthma and chronic renal failure. All patients were followed till 3, 6, 12 and 24 months.

Table 2: Etiology of heavy menstrual bleeding.

\begin{tabular}{|c|c|c|c|}
\hline \multicolumn{2}{|l|}{ Diagnosis } & Number & Percentage \\
\hline \multirow{4}{*}{$\begin{array}{l}\text { HMB } \\
\mathrm{N}=29(69 \%)\end{array}$} & HMB in $<40$ years & 13 & $31.0 \%$ \\
\hline & HMB in $>40$ years, wants conservative $t / t$ & 4 & $9.5 \%$ \\
\hline & HMB with systemic diseases & 8 & $19.0 \%$ \\
\hline & HMB in surgically high risk patients & 4 & $9.5 \%$ \\
\hline \multicolumn{2}{|c|}{ Fibroid uterus with normal cavity } & 6 & $14.3 \%$ \\
\hline \multicolumn{2}{|l|}{ Endometriosis } & 3 & $7.2 \%$ \\
\hline \multicolumn{2}{|l|}{ Adenomyosis } & 4 & $9.5 \%$ \\
\hline \multicolumn{2}{|l|}{ Total } & 42 & $100 \%$ \\
\hline
\end{tabular}

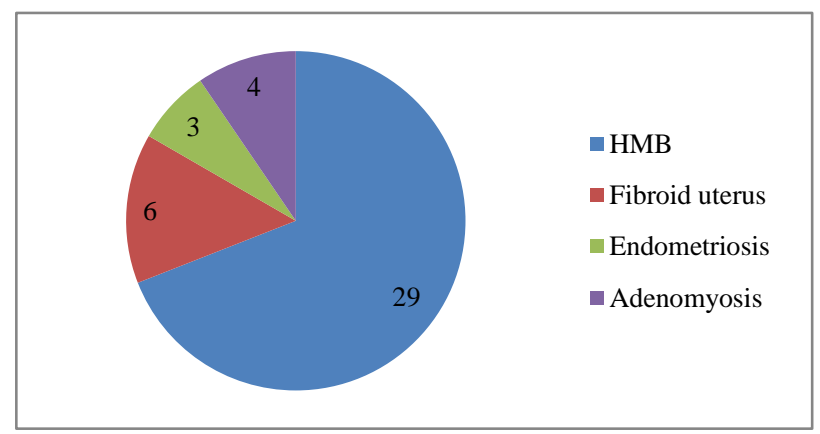

Figure 1: Etiological distribution of cases.
In first 3 months, $21 \%$ patients achieved normal menstrual cycle, and at 6 months $44.44 \%$ had scanty menstrual flow. After 1 year of use $81.5 \%$ achieved amenorrhoea whereas $11.1 \%$ had regular scanty bleeding. After 6 months of use there was significant reduction in pain and bleeding in cases of endometriosis, severe dysmenorrhea and chronic pelvic pain. In cases of adenomyosis there was decrease in uterine size as well as in menstrual bleeding. The most frequent complaint in initial 3 months was irregular heavy bleeding in $37.5 \%$ patients which reduced to $13.89 \%$ at 6 months and $0 \%$ at 1 year follow up. Irregular spotting was second most 
complaint in $32.5 \%$ patients in initial 3 months that persisted in $7.4 \%$ patients at 1 year follow up. In $4.7 \%$ patients, there was spontaneous expulsion of the device in first 3 menstrual cycles. 2 patients requested for removal of the device due continued irregular heavy bleeding and opted for hysterectomy. Post insertion pain and vaginal discharge was a common complaint in many patients in initial 3 months. After 3 months of use $57.5 \%$ patients were satisfied with the device and at the end of 1 year $92.5 \%$ were satisfied whereas $7.4 \%$ patients were not completely satisfied due to irregular spotting. After 2 years all patients who came for follow up were satisfied.

Table 3: Follow up of effects of LNG-IUS.

\begin{tabular}{|c|c|c|c|c|}
\hline Duration & $\begin{array}{l}3 \text { months } \\
\mathbf{N}=40\end{array}$ & $\begin{array}{l}6 \text { months } \\
\mathrm{N}=36\end{array}$ & $\begin{array}{l}12 \text { months } \\
N=27\end{array}$ & $\begin{array}{l}24 \text { months } \\
\mathrm{N}=12\end{array}$ \\
\hline Irregular heavy menses & $15(37.5 \%)$ & $5(13.89 \%)$ & 0 & 0 \\
\hline Irregular Spotting & $13(32.5 \%)$ & $4(11.1 \%)$ & $2(7.4 \%)$ & 0 \\
\hline Normal menses & $8(20.0 \%)$ & $6(16.7 \%)$ & 0 & 0 \\
\hline Scanty menstrual flow & $2(5.0 \%)$ & $16(44.44 \%)$ & $3(11.1 \%)$ & $1(8.4 \%)$ \\
\hline Amenorrhoea & 0 & $5(13.9 \%)$ & $22(81.5 \%)$ & $11(91.6 \%)$ \\
\hline Dysmenorrhoea & $27(67.5 \%)$ & $10(27.78 \%)$ & $1(2.78 \%)$ & 0 \\
\hline Expulsion & $2(5.0 \%)$ & 0 & 0 & 0 \\
\hline Lost to follow up & $2(5.0 \%)$ & $4(11.11 \%)$ & 9 & 15 \\
\hline Satisfied with device & $23(57.5 \%)$ & $31(86.11 \%)$ & $25(92.5 \%)$ & $12(100 \%)$ \\
\hline Device removed & 0 & $2(5.55 \%)$ & 0 & 0 \\
\hline
\end{tabular}

Table 4: Follow up of side effects.

\begin{tabular}{|c|c|c|c|c|}
\hline Complaints & $\begin{array}{l}\text { At } 3 \text { months } \\
N=40\end{array}$ & $\begin{array}{l}\text { At } 6 \text { months } \\
\mathbf{N}=\mathbf{3 6}\end{array}$ & $\begin{array}{l}\text { At } 12 \text { months } \\
N=27\end{array}$ & $\begin{array}{l}\text { At } 24 \text { months } \\
\mathbf{N}=11\end{array}$ \\
\hline Irregular heavy menses & $15(37.5 \%)$ & $3(8.3 \%)$ & 0 & 0 \\
\hline Irregular spotting & $13(32.5 \%)$ & $4(11.1 \%)$ & $1(3.7 \%)$ & 0 \\
\hline Post insertion pain & $9(22.5 \%)$ & 0 & 0 & 0 \\
\hline Post insertion Vaginal discharge & $14(35.0 \%)$ & $2(5.2 \%)$ & 0 & 0 \\
\hline
\end{tabular}

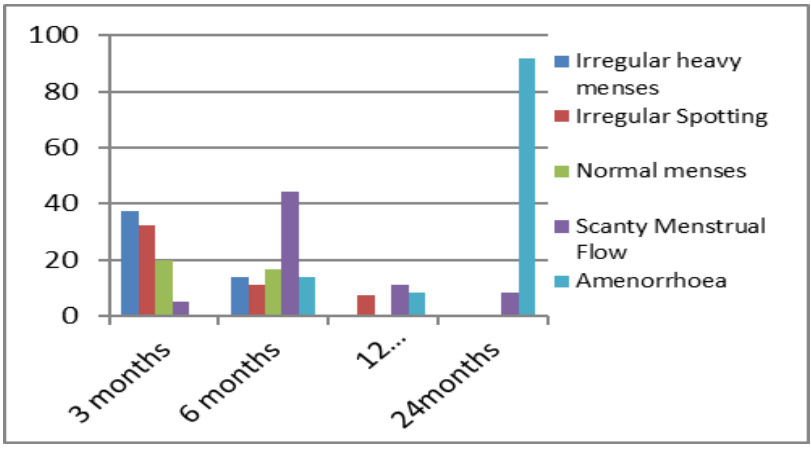

Figure 2: Effects on menstrual blood flow after LNGIUS insertion.

\section{DISCUSSION}

Approximately $30 \%$ of women of reproductive age experience heavy bleeding during menstruation. ${ }^{8}$ While in nearly half of all cases no organic pathology is found, a number of risk factors may contribute to the development of $\mathrm{HMB}^{8}$ In present study $69 \%$ patients had heavy menstrual bleeding with no identifiable cause. There were many treatment options including hemostatic drugs, hormones, endometrial ablation, LNG-IUS and the definitive treatment was hysterectomy. Medical management of HMB with hormones was really challenging due to poor compliance, side effects, cost, troublesome breakthrough bleeding and actual failures. According to Value study, a survey of outcomes of 37,000 hysterectomies, operative and postoperative complication was reported in $3.5 \%$ and $9 \%$ cases. $^{9}$ Postoperative mortality was $0.38 / 1000$ patients and psychological implication was seen in $35-45 \%$ patients. ${ }^{9}$ This was a well-recognized and established fact that the LNG-IUS offers potential therapeutic benefits in menorrhagia and symptomatic fibroids etc. ${ }^{10}$ However, it frequently produced menstrual disturbances initially that can limit its use by clinicians.

This prospective interventional study was done to evaluate the efficacy, acceptability and side effects of LNG-IUS in women with heavy menstrual bleeding. According to the ACOG (American College of Obstetricians and Gynecologists), the LNG-IUS appears to reduce menstrual blood loss significantly in women with HMB. ${ }^{11}$ 
In a study by Garg et al at six months post IUS insertion $10 \%$ had amenorrhea, $40 \%$ had irregular spotting (decreased flow), $23.33 \%$ had infrequent bleeding, 20\% had scanty regular bleeding and only two women $(6.66 \%)$ had irregular heavy bleeding. ${ }^{12}$ By the end of 12 months $90 \%$ of women in this group developed amenorrhea. In present study, at 6 months $13.9 \%$ had amenorrhea, $44.44 \%$ had scanty menstrual flow $11.1 \%$ had irregular spotting, $16.7 \%$ had normal menstrual cycle, and only 5 (13.89\%) patients had Irregular heavy bleeding. At 1 year of use $81.5 \%$ had amenorrhea, $11.1 \%$ had regular scanty flow and only $2(7.4 \%)$ had irregular spotting.

In a study by Kriplani et al HMB was cured in $77.7 \%$ patients at 3 months and in all patients at 36 months. ${ }^{13}$ There was a significant decrease in the number of bleeding days and decrease continued with increasing duration of treatment. $28.57 \%$ women developed amenorrhea at the end of six months whereas in our study $13.9 \%$ developed amenorrhea at six months, $81.5 \%$ at 12 and $91.6 \%$ at 24 months. In a Brazilian study, $44 \%$ of women reported amenorrhea at the 6th month of the study. ${ }^{14}$ In a study from Austria, 56\% subjects experienced an absence of menstruation, either completely from the time of insertion (47\%) or temporarily $(9 \%) .{ }^{15}$

Lockhat et al found significant improvement $(\mathrm{P}<0.05)$ in severity and frequency of pain and menstrual symptoms in $85 \%$ of patients. ${ }^{16}$ In a study by Garg et al there was a significant reduction in the dysmenorrhea associated with adenomyosis after LNG-IUS insertion and pain reduced further with duration of treatment. ${ }^{12} 56.6 \%$ women had no pain at the end of six months and $76.6 \%$ women had no pain at 1 year post LNG-IUS. In present study also all the patients with severe dysmenorrhea and endometriosis were relieved of their symptoms.

In a study by Tariq et al $38 \%$ women experienced vaginal spotting at the end of 3 months, however, at the end of one year it reduced to $3.5 \%$ and spontaneous expulsion of device was noticed in $8.8 \%$ women within 3 months. ${ }^{17}$ In present study $32.5 \%$ patients had irregular spotting after 3 months which reduced to $7.4 \%$ at the end of 1 year and $5 \%$ patients expelled the device within 3 months. Another $5.5 \%$ patients requested removal of device due to heavy bleeding even after 3 months.

In the study by Yazbeck et al $86.1 \%$ women with dysfunctional uterine bleeding were very satisfied with the treatment with LNG-IUS as an alternative to hysterectomy. ${ }^{18}$ The overall satisfaction scores were significantly more in the LNG-IUS group as compared to the hysterectomy group with $90 \%$ women being very satisfied with the treatment in the IUS group and only $50 \%$ being satisfied in the hysterectomy group. In present study $57.5 \%, 92.5 \%$ and $100 \%$ patients were satisfied with the device after 3 months, 1 year and 2 years respectively.

\section{CONCLUSION}

LNG-IUS is a safe, effective and acceptable mode of treatment of heavy menstrual bleeding. It can be a good alternative to hysterectomy for heavy menstrual bleeding due to many benign etiologies. It is associated with lesser side effects and higher satisfaction rate. LNG-IUS can be choice of treatment for entire reproductive years and it also helps in smooth transition to menopause. So, hysterectomy should be avoided for inappropriate reasons and feminity must be preserved.

Funding: No funding sources Conflict of interest: None declared

Ethical approval: The study was approved by the Institutional Ethics Committee

\section{REFERENCES}

1. Warner PE, Critchley HO, Lumsden MA, CampbellBrown M, Douglas A, Murray GD. Menorrhagia I: measured blood loss, clinical features, and outcome in women with heavy periods: a survey with follow up data. Am J Obstet Gynecol. 2004;190(5):1216-23.

2. Lethaby A, Hussain M, Rishworth JR, Rees MC. Progesterone or progestogenreleasing intrauterine systems for heavy menstrual bleeding. Cochrane Database Syst Rev. 2005;(4):CD002126.

3. Mansour D. Modern management of abnormal uterine bleeding: the levonorgestrel intra-uterine system. Best Pract Res Clin Obstet Gynaecol. 2007;21(6):1007-21.

4. Sheng J1, Zhang WY, Zhang JP, Lu D. The LNGIUS study on adenomyosis: a 3-year follow-up study on the efficacy and side effects of the use of levonorgestrel intrauterine system for the treatment of dysmenorrhea associated with adenomyosis. Contraception. 2009;79(3):189-93.

5. Lockhat FB, Emembolu JO, Konje JC. The efficacy, side-effects and continuation rates in women with symptomatic endometriosis undergoing treatment with an intra-uterine administered progestogen (LNG): a 3-year follow-up. Hum Reprod. 2005;20(3):789-93.

6. Gorgen H, Api M, Akça A, Cetin A. Use of the levonorgestrel-IUS in the treatment of menorrhagia: assessment of quality of life in Turkish users. Arch Gynecol Obstet. 2009;279:835-40.

7. Lete I, Obispo C, Izaguirre F, Orte T, Rivero B, Cornellana MJ, et al. The levonorgestrel intrauterine system (Mirena) for treatment of idiopathic menorrhagia. Assessment of quality of life and satisfaction. Eur J Contracept Reprod Health Care 2008;13(3):231-7.

8. El-Hemaidi I, Gharaibeh A, Shehata H. Menorrhagia and bleeding disorders. Curr Opin Obstet Gynecol. 2007;19(6):513-20.

9. McPherson K, Metcalfe MA, Herbert A, Maresh M, Casbard A, Hargreaves J, et al. Severe complications 
of hysterectomy: the VALUE study. BJOG. 2004;111(7):688-94.

10. Chrisman C, Ribeiro P, Dalton VK. The levonorgestrel-releasing intrauterine system: an updated review of the contraceptive and noncontraceptive uses. Clin Obstet Gynecol. 2007;50(4):886-97.

11. American college of Obstetricians and Gynecologists: Noncontraceptive uses of the levonorgestrel intrauterine system. ACOG Committee Opinion No. 337. Obstet Gynecol. 2006;107:1479-82.

12. Garg S, Soni A. A Non- surgical lifeline for Abnormal uterine bleeding (AUB) - the LNG IUS. Ind J Obstet Gynecol Res. 2016;3(1):23-27.

13. Kriplani A, Singh BM, Lal S, Agarwal N. Efficacy, acceptability and side effects of the levonorgestrel intrauterine system for menorrhagia. Int J Gynaecol Obstet. 2007;97(3):190-4.

14. Hidalgo M, Bahamondes L, Perrotti M, Diaz J, Dantas-Monteiro C, Petta C. Bleeding patterns and clinical performance of the levonorgestrel-releasing intrauterine system (Mirena) up to 2 years. Contraception. 2002;65(2):129-32.

15. Baldaszti E, Puchinger WB, L"oschke K. Acceptability of long-term contraceptive levonorgestrel-releasing intrauterine system (Mirena): a 3-year follow-up study. Contraception. 2003;67(2):87-91.

16. Lockhat FB, Emembolu JO, Konje JC. The efficacy, side-effects and continuation rates in women with symptomatic endometriosis undergoing treatment with an intra-uterine administered progestogen(levonorgestrel): a 3- year follow-up. Hum Reprod. 2005;20(3):789-93.

17. Tariq N, Ayub R, Jaffery T, Rahim F, Naseem F, Kamal M. Efficacy of Levonorgestrel Intrauterine System (LNG-IUS) for Abnormal Uterine Bleeding and Contraception. J Coll Physicians Surg Pak. 2011;21(4):210-3.

18. Yazbeck C, Omnes S, Lavenu VMC, Madelenat P. Levonorgestrel-releasing intrauterine system in the treatment of dysfunctional uterine bleeding: A French multicenter study. Gynecol Obstet Fertil. 2006;34:906-13.

Cite this article as: Singh K, Bharati G, Prasad D, Kumari S. Role of levonorgestrel releasing intrauterine device in management of heavy menstrual bleeding: a conservative approach. Int J Reprod Contracept Obstet Gynecol. 2017;6: 631-5. 